\title{
Pensando o caminhar como experiência estética e método de ficção literária
}

SOLNIT, Rebecca. A história do caminhar. São Paulo: Martins Fontes, 2016.

\author{
Wilck Camilo Ferreira de Santana (UFPE)* \\ https://orcid.org/0000-0001-5339-9914
}

\section{Resumo:}

Caminhar é uma atividade humana universal. Sua história é perpassada por uma espécie de prazer, liberdade e significados que pessoas diferentes procuram em momentos diversos. Pensando nessa direção, a história do caminhar proposta por Rebecca Solnit (2016) trilha percursos que vão desde a origem do bipedalismo até a caminhada na cidade. Para isso, a autora delineia argumentos que giram em torno do fato de que andar ereto é o primeiro marco do que viria a se tornar a humanidade. Entre os muitos caminhos que esse trajeto envolve, um deles está centrado na atividade de leitura do caminhar para descrever o mundo, fato que certamente contribuiu para que experiências itinerantes servissem como método de ficção. Ao considerar que há no fato de se deslocar na paisagem algo que estimula e aviva os pensamentos, Solnit evidencia que, no decorrer do tempo em que caminhar deixou de ser apenas uma atividade de descolamento para se tornar uma experiência, foram desenvolvidos métodos ficcionais como o fluxo de consciência e personagens andarilhos como o flâneur. Nessa rede imbricada de ideias e trajetos, acredita-se que as diferentes variações do deslocamento a pé representam ações políticas, estéticas e de grande significado social.

Palavras-chave: História do caminhar. Caminhar como método de ficção. Rebecca Solnit.

\section{Resumen:}

\section{Pensando el caminar como experiencia estética y método de ficción literaria}

Caminar es una actividad humana universal. Su historia está atravesada por una especie de placer, libertad y significados que personas distintas buscan en momentos diferentes. Pensando en esto, la historia del caminar de Rebecca Solnit (2016) abre caminos que van desde el origen del bipedalismo hasta el paseo por la ciudad. Para eso, la autora desarrolla argumentos acerca del hecho de que caminar sobre dos piernas es el primer presagio de lo que

* Mestrando em Teoria da Literatura pelo Programa de Pós-Graduação em Letras da Universidade Federal de Pernambuco (UFPE). E-mail: wilck.camilo@gmail.com 
se convertiría en la humanidad. Entre los muchos caminos que ese trayecto envuelve, uno de ellos es la actividad de lectura del caminar con el que se describe el mundo, hecho que ciertamente contribuyó para que experiencias itinerantes sirvieran como método de ficción. Con eso, al considerar que hay en el hecho de moverse en el paisaje algo que estimula y aviva los pensamientos, Solnit muestra que, en el transcurso del tiempo que caminar dejó de ser solamente una actividad física para convertirse en una experiencia, se desarrollaron métodos ficticios como el flujo de consciencia y personajes ambulantes como el flâneur. En esa red entrelazada de ideas y caminos, se cree que las diferentes variaciones de los desplazamientos a pie representan acciones políticas, estéticas y socialmente significativas.

Palabras clave: Historia de caminar. Caminar como método de ficción. Rebecca Solnit.

Editora colaboradora da Hasper's Magazine, uma das mais aclamadas revistas estadunidenses, Rebecca Solnit se dedica a escrever a respeito de uma variedade de temas; entre eles o meio ambiente, a política e a arte. Ao longo da carreira, recebeu importantes bolsas de estudos, como a NEA Literature, por escrever sobre os efeitos da tecnologia nas artes e nas humanidades. Escrito nos anos finais da década de 1990 e publicado originalmente em inglês, $A$ história do caminhar (2016) é um retrato da infinita gama de possibilidades que o ato de se deslocar no espaço proporciona. Analisando temas que vão desde a evolução anatômica até a caminhada na cidade, a autora investe no pressuposto de que, enquanto seres humanos, nossa tendência é considerar que os alicerces da cultura são naturais. Mas todo alicerce foi construído, tudo tem uma origem, e o caminhar não escaparia à regra. Na grande maioria das vezes, caminhar não passa de uma questão prática na qual pessoas se locomovem de um lugar para outro. Seu objeto é a maneira como exercermos atos universais com significados particulares, pois da mesma maneira que diversas ações podem aparecer submersas de significados culturais, com o ato de caminhar não é diferente. É por isso que a sua história passa a fazer parte da história da imaginação e da cultura, perpassada por uma espécie de prazer, liberdade e significados que pessoas diferentes procuram em momentos diversos. Foi assim que o caminhar deu forma a estradas, rotas, trilhas, ruas e avenidas, gerando uma infinidade de lugares e de hábitos, modelando cidades, criando mapas e uma vasta biblioteca de literatura.

Trilhando os passos da autora, em certo sentido a escrita literária está ligada ao caminhar. Escrever é abrir um caminho no terreno da imaginação ou apontar novas atrações num itinerário familiar. Ler é percorrer esse terreno tendo o autor como um guia. Tendo isto em mente, se existem caminhadas que lembram livros, também existem livros que lembram caminhadas e usam a atividade de leitura do caminhar para descrever um mundo. Um memorável exemplo é $A$ divina comédia, de Dante Alighieri, na qual os três reinos espirituais da vida após a morte são explorados numa espécie de relato. Quer dizer: o movimento da narrativa é produzido pelo movimento das personagens através de uma paisagem imaginária. Outros exemplos que ilustram o pensamento da autora são textos como o de George Walker, com seu nome apropriado [walker no inglês significa andarilho], que inaugurou o 
século XIX com o romance The Vagabond [ $O$ vagabundo], de 1814; e o poema "Walking to Work" [A pé para o trabalho], publicado em 1957 por Frank O'Hara. São textos como esses que nos levam a pensar que caminhar é uma maneira de garantir a erosão da mente, do corpo e da paisagem, e que quando nos entregamos aos lugares, eles nos devolvem a nós mesmos; quanto mais os conhecemos, mais o semeamos com a cultura invisível de lembranças e associações, ao passo que os lugares novos oferecem novos pensamentos, novas possibilidades. Explorar o mundo, destaca Solnit, é uma maneira de explorar a mente, e o caminhar percorre as duas topografias.

Jean-Jacques Rousseau observou em seu livro autobiográfico: Confissões (1782), que só conseguia meditar quando caminhava. Parado, deixava de pensar. É partindo de perspectivas como essa que a autora defende que a história do caminhar como um ato consciente e cultural, e não um meio para chegar a um fim, tem apenas alguns séculos de idade no Ocidente e se inicia na Europa com Rousseau. Sempre ilustrando seu pensamento, Solnit oferece uma série de exemplos de textos que ressaltam essa relação entre o caminhar e a mente, como é o caso do escritor inglês John Thelwall que, em 1793, assim como os antigos, se dedicando às suas meditações a pé, inspirou-se para escrever o seu livro The Peripatetic [0 peripatético]. Aristóteles, nesse contexto, é um dos responsáveis pela crença de que os antigos caminhavam para pensar, sobretudo quando ele se viu pronto para abrir uma escola em Atenas, e a cidade designou-lhe um terreno. Era esse um lugar onde as pessoas caminhavam para lá e para cá, e por esse motivo diriam, posteriormente, que o próprio Aristóteles lecionava andando para os filósofos ali formados, então chamados de peripatéticos. Enxergando no caminhar algo que estimula e aviva os pensamentos, de modo que o corpo precisa estar em movimento para acionar a minha mente, para Solnit Rousseau pinta o caminhar como um exercício de simplicidade e um método de contemplação. No período que escreveu os Discursos (1755) ele costumava andar sozinho pelo Bosque da Bolonha, pensando e repensando a matéria de obras ainda por escrever. Já no fim da vida, escreveu $O s$ devaneios do caminhante solitário (no original, Les rêveries du promeneur solitaire, 1782). Cerca de um século e meio mais tarde, James Joyce e Virginia Woof, tentando descrever o funcionamento da mente, desenvolveriam a técnica chamada de fluxo de consciência. Em seus respectivos romances, Ulisses (1922) e Mrs. Dalloway (1925), os pensamentos e recordações dos personagens desenvolvem melhor durante caminhadas. Esse tipo de raciocínio desestruturado e associativo é o tipo mais comumente relacionado ao caminhar e sugere que o ato nada tem de analítico: é improviso. Foi, portanto, com base nessas explorações que veio a surgir personagens como o flâneur, passando esse a incorporar uma série de poesias, contos e romances a partir do século XIX. Em vista de associações como essas, Solnit acredita ser o livro Os devaneios, de Rousseau, umas das primeiras descrições da relação que se busca estabelecer entre o pensar e o caminhar.

Deslocando a questão para o campo da evolução da espécie, caminhar ereto é o primeiro marco daquilo que viria a se tornar a humanidade. A tese assegurada pela autora gira em torno de que o caminhar sobre duas pernas foi um mecanismo que provocou a expansão de nosso cérebro. Embora o debate a respeito da origem do bipedalismo esteja repleto de discussões minuciosas, é certo que a singularidade dos seres humanos está 
marcada pela consciência. Pensando assim, o nosso corpo é diferente de tudo na terra e, por essa razão, pode-se dizer que de certo modo ele deu forma a essa consciência. Isso corresponde ao fato de termos ficados de pé e passado a caminhar. Os hominídeos haviam aprendido a andar para poderem explorar a savana, e a savana pareceria ser a imagem da liberdade, o espaço ilimitado no qual as possibilidades eram igualmente ilimitadas. A transição para o bipedalismo, assinala Solnit, não criou inteligência, mas tornou possível seu surgimento. Foi a transformação anatômica que nos tirou do reino animal para acabar ocupando nossa posição de solitária dominância sobre a Terra.

Podendo considerar $A$ história do caminhar um trajeto de avanços e retomadas, tempos a frente de toda essa evolução anatômica, é focando nos caminhantes mais significantes da história que a autora reconhece que Wordsworth transformou o caminhar em algo novo, fundando a linhagem daqueles que caminham por caminhar e pelo prazer de se ver na paisagem. Coube a Wordsworth apresentar o caminhar como ato cultural e experiência estética. Da mesma maneira que a revolução cultural do século XII introduziu o amor romântico primeiro como tema literário, depois como uma maneira de vivenciar o mundo, o século XVII criou um gosto pela natureza sem o qual os irmãos William e Dorothy Wordsworth não teriam escolhido percorrer a pé longas distâncias no meio do inverno e se desviar de seu percurso para admirar cachoeiras. Não que ninguém admirasse uma queda d'água antes disso, mas em torno desse feito surgiu uma estrutura cultural. Não há como mensurar o impacto que essa convulsão teve sobre os gostos pela natureza e a prática de caminhar. Ela reformulou os mundos físico e intelectual, dirigiu milhares de viajan- tes para destinos até então desconhecido, criou inúmeros parques, trilhas, clubes e um vasto corpo de arte e literatura quase sem precedentes antes do século XVIII. O gosto pelo caminhar tornou-se algo que acabaria democratizando muitas áreas ao longo do século XX. Antes disso, a paisagem ainda não era, como viria a ser, um tema relevante para a pintura e para a poesia, tendo em vista que, até então, caminhar era movimento e não experiência.

Foi devido a todas essas transformações que no universo secular o caminhar passou a ser imaginado como diversão recorrendose a equipamentos e técnicas para aumentar o conforto e a eficiência do corpo. Passear na plaza no centro da cidade passou a ser um costume social, um subconjunto do caminhar com ênfase no movimento lento e majestoso. Não era uma maneira de chegar a algum lugar, mas de estar lá. É estranho, menciona Solnit, que o paseo tenha deixado de ser um acontecimento pedestre para se tornar veicular. Os carros funcionam melhor como engenhos excludentes. Mesmo que sejam conduzidos de maneira mais lenta, eles ainda não permitem o encontro direto e o contato fluido que o caminhar possibilita. É seguindo esse raciocínio que a autora acredita que algumas forças da sociedade moderna parecem se colocar contra o tempo, o espaço e a vontade de caminhar, contra a versão de humanidade que o ato personifica. A capacidade de apreciar esse tempo livre, parece estar desaparecendo cada vez mais e a luta contra essa falência da ação e da imaginação pode ser tão importantes quanto as batalhas pela liberdade política. Geralmente se imagina que caminhar é não fazer nada diante de uma cultura de produtividade por ser essa uma atividade física que nada produz a não ser pensamento, experiências e chegadas, o que significa dizer 
que caminhar é um estado no qual a mente, o corpo e o mundo se alinham, como se a caminhada produzisse um raciocínio, sugerindo que a mente é - também - uma espécie de paisagem e que para conhecê-la melhor é preciso caminhar. Talvez seja daí que venha a utilidade de andar para os mais diversos pensadores, poetas, artistas e escritores de diferentes épocas e partes do mundo.

Em linhas gerais, $A$ história do caminhar de Solnit testifica que os pés foram um importante mecanismo de desbravamento do mundo e da mente. A partir deles, com o tempo, caminhar passou a ser uma atividade física, política e de exploração. Foi assim que se descobriram as cidades e construíram pontes entre mundos tão distintos e distantes. Caminhar passou a ser uma maneira de criar o mundo e também de estar nele. Seja no campo ou na cidade, depois dessa revolução feita com os pés, as pessoas não deixariam mais de caminhar. Enquanto de um lado, por exemplo, essa história no campo se mostraria repleta de pessoas que desejavam se apresentar saudáveis, irmanadas com a natureza, na cidade, outros andarilhos encarnariam papéis radicais, determinados a destruir aos poucos as leis e autoridades que sufocam as pessoas, foi assim que andar com outras pessoas veio a se tornar armaduras da sociedade civil. Caminhar por prazer entrou para o repertório de possibilidades humanas. Tornou-se uma das forças que criou o mundo contemporâneo. Antes do século XVIII, parece que poucas pessoas percorriam as ruas a pé por prazer, e somente no século XIX é que surgem lugares limpos, seguros e iluminados como as cidades modernas. Esse movimento deu origem a uma nova imagem do que significa ser humano, uma imagem de alguém dotado da liberdade. Caminhar, por fim, veio a ser um estado observador, de sentidos aguçados. Um bom estado para quem precisa refletir ou criar. Com isso, o mundo passou a ser visto como um repositório da história, e caminhar uma maneira de ler essa história, ou de escrevê-la. E foi esse um dos fatores que, como pensa Solnit, levou poetas, artistas, estudiosos e escritores do mundo inteiro a se dedicar à atividade como um meio de desbravar o mundo, mas também de criar, o que fez do caminhar, para a literatura, um método de ficção. 